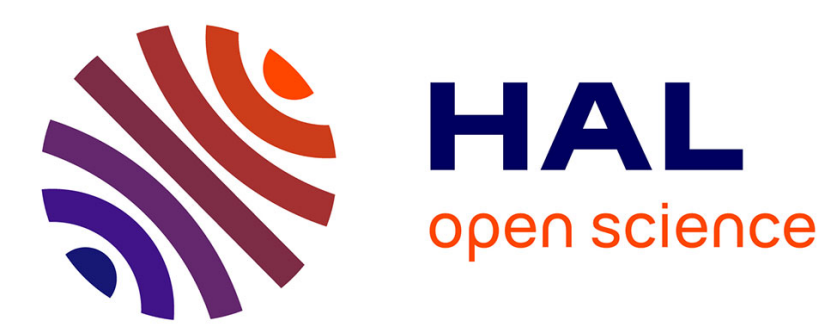

\title{
The Impact of Globalization on Food and Agriculture: The Case of the Diet Convergence
}

\author{
Thierry Brunelle, Patrice Dumas, François Souty
}

\section{To cite this version:}

Thierry Brunelle, Patrice Dumas, François Souty. The Impact of Globalization on Food and Agriculture: The Case of the Diet Convergence. Journal of Environment and Development, 2014, 23 (1), pp.41-65. 10.1177/1070496513516467 . hal-01137817

\section{HAL Id: hal-01137817 https://hal.science/hal-01137817}

Submitted on 3 Apr 2015

HAL is a multi-disciplinary open access archive for the deposit and dissemination of scientific research documents, whether they are published or not. The documents may come from teaching and research institutions in France or abroad, or from public or private research centers.
L'archive ouverte pluridisciplinaire HAL, est destinée au dépôt et à la diffusion de documents scientifiques de niveau recherche, publiés ou non, émanant des établissements d'enseignement et de recherche français ou étrangers, des laboratoires publics ou privés. 


\title{
The Impact of Globalisation on Food and Agriculture: the Case of the Diet Convergence
}

\author{
T. Brunelle* ${ }^{* \dagger}$ P. Dumas ${ }^{\dagger \dagger}$ F. Souty ${ }^{\dagger \S}$
}

Postprint

Keywords: globalisation, shift in diets, land-use change.

* The authors wish to thank Chad Boda, Bruno Dorin, Franck Lecocq and Paul Weaver for their valuable comments on previous versions of this article. We gratefully acknowledge financial support by the GIS Climat Environnement Société ACACCYA project and the FP7 GLOBIS project.

\footnotetext{
${ }^{*}$ Corresponding author.

Organisation: Centre International de Recherche sur l'Environnement et le Développement

Address: Campus du Jardin Tropical

45 bis, avenue de la Belle Gabrielle

94736 Nogent-sur-Marne Cedex

Phone: +33 (0)143947365 - Mail : brunelle@centre-cired.fr

${ }^{\dagger}$ Centre International de Recherche sur l'Environnement et le Développement

${ }^{\ddagger}$ Centre de Coopération Internationale en Recherche Agronomique pour le Développement

${ }^{\S}$ Laboratoire des Sciences de l'Environnement et du Climat
} 


\section{Biographies}

Thierry Brunelle, $\mathrm{Ph}$. D., is researcher in economy at CIRED. He is currently working on the development of the land-use model NLU and on its coupling to the CGE model Imaclim-R. He was involved in several national and international research projects, including multidisciplinary collaborations with climatologists.

Patrice Dumas is a CIRAD researcher in CIRED, working on the agricultural sector long-term foresight under food security and climate policies constraints. In addition to his implication in the development of the NLU model, he is also in the Agrimonde-Terra Foresight on Land uses and food (in)security.

François Souty, Ph. D., is researcher in biophysics at CIRED. He participated in the development of the NLU model, notably in integrating biophysical data. 


\begin{abstract}
Globalisation drives a process of diet convergence among developing and developed countries that challenges the predictions about future patterns of food consumption. To address this issue, the objective of this paper is to map the range of the possible future diet changes, and to explore their impact on agriculture using the NLU land-use model. This model computes agricultural intensification in the crop and livestock sectors at the global scale, based on an architecture accounting for the different types of food calories. By considering four scenarios built upon distinct assumptions regarding diet convergence, this paper sheds light on the pivotal role of diet changes as drivers of tensions on agriculture and land-use, and shows the uncertainty associated with processes of diet convergence for foresight exercises on food and agriculture. Finally, the interactions between food production and the other land-use patterns are explored by testing the sensitivity of our results to assumptions regarding biofuel production, deforestation, potential crop yields and nutrient use efficiency.
\end{abstract}




\section{Introduction}

The last decades have witnessed important evolutions of dietary habits in many developing and emerging countries, both in quantity and composition. Diet changes have been especially strong in Latin America and Asia (excluding India), where the caloric intake per capita rose on average by $60 \%$ between 1960 and 2006, while the share of animal products in total food consumption grew from $7 \%$ to $16 \%$ (Dorin, 2011). Fueled by such changes in food consumption and a nearly doubling world population, the production of food crops grew globally by 170\% between 1960 and 2006 , inducing significant changes in terms of intensification (e.g., consumption of fertilisers, use of concentrates for feeding animals) and extensification (e.g., deforestation) (Alexandratos and Bruinsma, 2012). As a result, shift in diets is now a key issue for climate change mitigation (Stehfest et al., 2009; Popp et al., 2010).

Foreseeing the future evolution of diet is particularly challenging as it is shaped by both pecuniary considerations, linked to food prices, and by subjective tastes or cultural preferences. An additional difficulty is the influence of globalisation on the evolution of diets. The growing interconnectedness of places and people through markets, information and capital flows, human migration, and social and political institution that characterises globalisation (Lambin and Meyfroidt, 2009) is actually predicted to cause the standardisation of tastes and desires and the spreading of Western lifestyles (Stephan et al., 2011), thus creating new possible pathways of diet evolution.

This uncertainty about future diet evolution has important consequences, as it challenges the reliability of foresight analyses on land-use and agriculture. To address this issue, the objective of this study is threefold: (i) to map the range of the possible evolutions of diet, taking into account the influence of globalisation; (ii) to explore the impact of each of these scenarios on agriculture; (iii) to provide insights on how each of these possible futures interact with the other uses of land (e.g., bioenergy production, deforestation) and how the resulting tensions on landuse could be mitigated.

We first review the main projections of food consumption that have been undertaken over the last ten years, with a specific focus on the role of globalisation and diet convergence as determining factors. Then, we test the impact on agriculture of each of these food foresights. To test these scenarios, we use them, with two additional contrasting scenarios of diet convergence, as exogenous inputs in the global model of land-use and agricultural intensification Nexus Land-Use (NLU) (Souty et al., 2012). This model is particularly suited to this study as it distinguishes between plant food, ruminant and monogastric calories, and associates them to a specific production process.

The following section reviews the main recent food foresights and describes the diet scenarios studied. Section 3 details the methodology. Results are presented in section 4. Finally, the sensitivity of our results to assumptions regarding deforestation, biofuel production, potential crop yield and nutrient use efficiency is tested in section 5 . 


\section{Diet Evolution: Mapping the Range of the Possible Futures}

\subsection{Globalisation and Diet Convergence in the Main Recent Food Foresights}

As shown on figure 1 , the consumption of plant food and animal calories ${ }^{1}$ has rapidly increased in some regions between 1961 and 2007, especially in China (plant food calories $=+1.1 \%$ p.y. , animal calories $=+5.5 \%$ p.y.) and Brazil (plant food calories $=+0.5 \%$ p.y. , animal calories $=+1.7 \%$ p.y.). These major dietary changes are generally attributed to economic growth and to the influence of globalisation. The greater interconnecdeness characterising the globalisation process is actually considered to favour the disconnect between locations of production and consumption, to propell changes in agricultural production and retailing system, with international processing industries and supermarkets facilitating diet diversification, and to accelerate the nutritional transformation towards a globalised dietary pattern.

Extending observed trends over the next decades cannot be simply used to project future food consumption. For example, by using the diet evolution trends over the 1961-2001 period, the total food availability would reach,e.g., more than $14000 \mathrm{kcal} / \mathrm{cap} /$ day in China. This figure is far from being reasonable, keeping in mind that the energy requirement recommended for an adult ranges between 2100 and $4500 \mathrm{kcal} / \mathrm{cap} /$ day depending on ones metabolism and physical activity ${ }^{2}$.

[Figure 1 here : Evolutions of the consumption of plant food (up) and animal (down) calories around the world (Dorin, 2011).]

Given the difficulties raised by a simple continuation of past trends, alternative methodologies are necessary to draw realistic projections that would correctly account for saturation levels. In this paper, we consider the results of three foresight exercises which are often used as reference points in the scientific community: The Millennium Ecosystem Assessment (MEA) (MA Board, 2005), Tilman et al. (2011) and the 2012 revision of the FAO projection "World Agriculture towards 2030/2050" (Alexandratos and Bruinsma, 2012).

The MEA explores the implications for ecosystem services of four scenarios developed following a procedure mixing qualitative storylines and quantification. In this assessment, food projections are driven by food prices, per capita income, and total population. The level of income, population, as well as the sensitivity of food consumption to changes in incomes, are defined in accordance with the qualitative storylines.

These qualitative storylines have been designed based on a survey of the needs of the intended users and on interviews with 59 leaders in NGOs, governments, and

\footnotetext{
${ }^{1}$ Expressed in terms of food availability. See definition in section 2.2

${ }^{2}$ Selecting alternative time period to base the projection (e.g., 1990-2000) yield similar unrealistic path of diet evolution
} 
businesses from five continents. Through this expert consultation, globalisation has been identified, along with the reactive or proactive approach to ecosystem management, as a critical determinant of the future state of ecosystems. There was however a wide disagreement on the expected consequences of globalisation. While some experts pointed out the virtues of increased communication among people, others expressed concerns about the environmental impact of a global homogenisation of preferences. This diversity of viewpoints about the same issue was not specific to globalisation. For instance, respondents did not agree on whether inequality could or even should be truly reduced (MA Board, 2005, Chapter 5). The globalisation issue was nevertheless characterised by the difficulty to agree on its definition (e.g., restricted or not to international trade between poor and rich countries), which was at the root of some divergences on its expected consequences for ecosystems.

Globalised MEA scenarios - Global Orchestration and TechnoGarden - are characterised by rapid income growth in all countries, increasing trade liberalisation, and urbanisation. These scenarios are also associated with large investments in agricultural research and infrastructure enabling substantial improvements in crop yields and relatively weak increases in food prices. Finally, the income elasticities of the demand for meat becomes relatively higher as the level of globalisation grows.

Tilman et al. use a different methodology to evaluate the environmental impacts of different ways to meet the demand for crop production in 2050. The per capita demands of calories and proteins is forecast by using an econometric relationship with the per capita GDP. A Kuznet's curve, assuming some degree of economic convergence of the poorest countries towards the richest ones, is used to estimate GDP in 100 nations, which are then aggregated into seven economic groups ranked according to their per capita GDP from the richest (A) to the poorest (G). Tilman et al.'s projections therefore imply a significant convergence of diet among countries. According to their results, growth rates of per capita crop calories ${ }^{3}$ range between $+20 \%$ and $+107 \%$ for groups B to $\mathrm{F}$ against $+10 \%$ for the group A.

Alexandratos and Bruinsma (2012) is an update of the FAO projections regarding food consumption and agricultural production until to 2050. The study is mostly based on a methodology that draws on expert views. According to their narrative, changes in diet will be a significant driver of the growth in the demand for agricultural products, however, convergence of diets towards developed countries should not completely level out consumption styles across developed and developing countries. In particular, substantial differences may remain in the consumption of meat and milk. Regional food habits, such as taboos on cattle meat in India or pig meat in Muslim countries, will slow the "livestock revolution" experienced by countries like China, Brazil or Malaysia. Alexandratos and Bruinsma (2012) analysis is thus based on a foresight vision where globalisation will coexist with regional cultural references. In contrast to Tilman et al.'s paper, in which food consumption is strongly connected to growth in per capita GDP, Alexandratos and Bruinsma (2012) estimate that regional specificities will significantly influence the way diets will change

\footnotetext{
${ }^{3}$ Including food and feed
} 
with income growth.

Based on the above methodological discussion, we consider four diet scenarios. The first one is based on the data provided by Alexandratos and Bruinsma (2012). The second diet scenario corresponds to the MEA "Global Orchestration" scenario. The scenario of food consumption built by Tilman et al. (2011) cannot be included in our simulations, as animal products are not considered by Tilman et al. (2011). Nevertheless, in terms of crop production, this scenario is similar to the MEA "Global Orchestration" scenario, both forecasting exercises yielding a $\sim+90 \%-+100 \%$ growth in crop production to 2050 . Finally, to mark out the range of the possible futures, we consider two additional scenarios, illustrating two contrasting visions of the diet convergence: a scenario called "US Convergence" assuming a convergence of all regions towards US diets in 2001, and a scenario based on a convergence towards sustainable feeding conditions, through (i) the reduction in malnutrition and in the excesses in nutritional intake, (ii) the reduction in the share of animal calories in diets, and (iii) the reduction of food waste throughout the consumption process. This last scenario is taken from the "Agrimonde 1" scenario of the French foresight exercise "Agrimonde" (Paillard et al., 2011b,a).

Our study aims mainly at comparing different assumptions on the process of diet convergence. As previoulsy shown, these assumptions result themselves in the various food foresights considered from assumptions on the growth of the per capita GDP and population, and are generally independent from the land-use scenario. Our work does not rely on any assumptions on the per capita GDP (e.g., regarding the growth in crop yield). Our demographic scenario is similar to the one developed by Alexandratos and Bruinsma (2012) and Tilman et al. (2011) (see section 3.2), but is higher than the projections used in the MEA (8.2 Mds in 2050 against $9.1 \mathrm{Mds}$ in our study). Thus, except for the MEA, our study is consistent with the forecasting exercises considered regarding the underlying assumptions of the diet scenarios. Consequently, our diet scenario corresponding to the MEA "Global Orchestration" must be viewed as an exaggeration of the future envisaged by the MEA.

\subsection{Quantification of the Food Availibilities in the Four Scenarios Studied}

All diet scenarios are expressed in kilocalories and in terms of food availability. This availability reflects the quantity of calories available to consumers, at both home and outside the home. This quantity includes calories that are lost between the purchase and consumption of the products and should not be confused with the quantity of calories actually consumed, which is difficult to estimate. Three types of calories are considered: plant food, ruminant (from cattle, sheep and goats) and monogastric (from pig and poultry).

Food availabilities provided by Alexandratos and Bruinsma (2012) are corrected to include animal fat and exclude fisheries products. The quantifications of the MEA "Global Orchestration" are taken from Paillard et al. (2011b), as well as the food availability of the "Agrimonde 1 " scenario. 
Due to the different regional aggregations used in the food foresights considered, some approximations have been made to adapt the diet scenarios to the NLU framework (see the table of correspondence of the regional aggregations provided in the Supplementary Materials). To disaggregate a given region, the diet of the aggregated region is simply attributed to the sub-region. Thus, the data on the diet scenarios at the regional level must be analysed with caution.

In this study, the MEA Global Orchestration / Tilman et al. scenario is denoted as MEA_GO, the Alexandratos and Bruinsma scenario as "FAO", "Agrimonde 1" as "AG1", and the scenario "US Convergence" as "USConv".

As shown in Figure 2, the total food availability per capita in 2005 and in the AG1 scenario are globally similar, with a total global average of around 2900 $\mathrm{kcal} /$ day/cap. The diet composition in AG1 is slighly different, with less ruminant calories and more plant food and monogastric calories than in 2005. On the other hand, there are large discrepancies in the regional distribution (see Figures 3 and 4), with a more equal distribution in the AG1 scenario than in 2005.

In the FAO scenario, the total food availibility per capita is $9 \%$ higher than in 2005 , mainly due to the rise in consumption of animal calories $(+22 \%$ of ruminant calories, $+25 \%$ of monogastric calories). In this scenario, the gap between the developing and the western countries is reduced compared to the 2005 situation. The catch up is however slower in India and Africa, where the consumption of animal calories remain significantly lower than in other regions.

The growth in food availability in the MEA_GO scenario over 2005-2050 amounts to $20 \%$, largely driven by a strong rise in consumption of animal calories $(+76 \%$ of ruminant calories, $+63 \%$ of monogastric calories). The catch up of developing towards developed countries is larger than in the FAO scenario for both plant food and animal calories, mirroring the higher level of diet convergence assumed in this scenario. It is however important to note that in the MEA, India is aggregated with the other Asian countries into a single region, thus the data provided here on this country are not completely relevant given the methodology of disaggregation described above.

Given the assumption of a full convergence of every region towards the US food habits in 2050, the growth in food availability in the USConv scenario is very high $(+45 \%$ over $2005-2050)$, especially for ruminant $(+163 \%)$ and monogastric calories $(+141 \%)$.

[Insert Figure 2 here : World average food availability in 2005 and in 2050 according to the four diet scenarios studied (in kcal/cap/day).]

[Insert Figure 3 here : Regional food availabilities of total calories (in $\mathrm{kcal} / \mathrm{cap} /$ day).]

[Insert Figure 4 here : Regional food availabilities of animal calories 
(in kcal/cap/day).]

\section{Data and Methods}

\subsection{Assessing the Impacts of Various Diet Scenarios on Agriculture and Land-Use with the NLU Model}

To explore the impacts of these four diet scenarios on agriculture and land-use, we use the Nexus Land-Use model (NLU), which simulates changes in the agricultural sector at the global level under various assumptions regarding biomass demand (Souty et al., 2012). Food markets are not represented in this study, as we test exogenous pathways of dietary change. Food demand is therefore not affected by price changes. An alternative modelling choice would have changed the diet scenarios considered and blur the results.

The NLU model is particularly suited for this study for several reasons. First, the model relies on resource-use balance of crop and livestock products expressed in kilocalories (kcal), the common unit used for nutrition $(1 \mathrm{kcal}=4.1868 \mathrm{~kJ})$. At the model base year (2001), the resource-use balance is established on the basis of data from the global database Agribiom (Dorin, 2011). Using calories makes it possible to deal with different types of biomass for human consumption. In NLU, plant food, ruminant and monogastric calories are thus separated, and each type of calorie is associated with a specific production process.

Based on the livestock model provided by Bouwman et al. (2005), monogastric animals are fed by a mix of food crops, residues and fodder. The production of ruminants is either intensive or extensive. In the intensive system, ruminants are fed by a mix of food crops, residues, fodder and grass, while they are exclusively fed with grass in the extensive system. In the NLU model, the frontier between the intensive and extensive systems evolve according to relative profits in each system. Crop- and pastureland for producing food crops and grass are endogenously modeled in NLU. On the other hand, the evolution of fodder area is mainly exogenously set (see infra).

The production of plant food calories (for food and feed use) is represented using a representative crop, as follows: at the base year, a representative potential yield is computed on a $0.5^{\circ} \times 0.5^{\circ}$ grid from the potential yields given by the vegetation model LPJmL for 11 crop functional types (CFT). Land classes grouping together grid points with the same potential crop yield are set up. Actual crop yield in each land class is determined by a non-linear function of chemical inputs, such as fertilisers and pesticides. In each land class, consumption of chemical inputs and associated crop yields are determined by cost minimisation. In this ways, NLU makes it possible to represent the land-fertiliser substitution by taking into account the land heterogeneity.

Two categories of crops are distinguished in NLU: "dynamic" crops, corresponding to most cereals, oilseeds, sugar beet and cassava, with a small share of fodder 
crops and "other" crops including sugar cane, palm oil, vegetables and fruits, some fodder crops and remaining crops. "Dynamic" crop yield is endogenously determined, taking into account biophysical constraints and the amount of fertiliser used. The share of "other" crops in total crop production is supposed to be constant over the projection period 2005-2050. The "other" crop yield is an exogenous parameter calculated based on the projections from Alexandratos and Bruinsma (2012).

In 2001 (model base year), the model is based on the land-use map from Ramankutty et al. (2008). The total cropland area amounts to 1472 Mha, divided between 748 Mha of "dynamic" crops and 724 Mha of "other" crops. Production on "dynamic" cropland represents $75 \%$ of the global calorie production reported by the global database Agribiom.

In NLU, three categories of pastures are distinguished. The two first are intensive and extensive pastures, corresponding to the two livestock production systems represented in NLU. A third category, called "residual"', is considered. This latter use of land is assumed to be inefficient in the sense that production cost is not minimised. The residual pastures may correspond in reality to lands extensively managed because of geographic and institutional limitations (e.g. high transport cost, inadequate topography or specific land property rights). Residual pastures have the same yield as extensive pastures. In the model base year, the total pasture area amounts to 2694 Mha following Ramankutty et al. (2008). The quantification of total permanent pasture area is however highly uncertain due to the unclear distinction between rangeland and grassland pastures in national inventories (Ramankutty et al., 2008). In this study, we choose the Ramankutty et al. (2008) dataset, which is believed to be more reliable than the FAO statistics, as the authors use a specific method relying both on satellite data and national inventories.

The international trade is modelled by using a pool representation without any consideration of the geographic origin of goods. Imports and exports are determined by relative regional calorie prices, taking into account a simple representation of imperfect competition and food sovereignty considerations. Coefficients governing the trade volume are calibrated against the year 2001 using Agribiom data. The (regional) price-elasticities of exports are calibrated against the 1961-2006 period.

The performances of the model have been investigated through a backcasting exercise over the period 1961-2006. Estimations of cropland areas (sum of areas for "dynamic" and "other" crops) in each region are evaluated against historical data in each region from Ramankutty and Foley (1999). At the global scale, the simulated cropland area fit observations rather well. The root-mean-square errors (RMSE) amounts to 52.3 Mha p.y. in absolute terms and $3.6 \%$ p.y. in relative ones.

The impacts on agriculture and land-use are mainly studied from an ecosystem preservation point of view, leaving the assessment of the economic impacts to further studies. For this purpose, we use four indicators: (i) the total cropland area ("dynamic" + "other"), (ii) the share of intensive ruminant production in total ruminant production, which mirrors the level of intensification in the livestock production sector, (iii) the consumption of fertilser inputs ("dynamic" only) and (iv) the yield gap ("dynamic" only). The yield gap is defined as follows: 


$$
\text { Yield gap }=\frac{\text { Potential yield }- \text { Actual yield }}{\text { Potential yield }- \text { Minimum yield }}
$$

The minimum yield is calibrated so as to minimise the error between modeled and observed crop yields over the 1961- 2006 period. The crop yield and the consumption of chemical inputs are not calcultated by NLU for the "other" crops, explaining why the two last indicators are restricted to the "dynamic" crops.

In section 5, we use the world calorie price as a global indicator of tensions on land-use. The world calorie price is the mean of regional prices weighted by the share of each region in total export. Regional prices are not set on food markets but are equal to the production costs on the marginal land, following Ricardian theory.

\subsection{Scenario Parameters}

For a relevant comparison, the four diet scenarios are studied using the same hypothesis on demography, fertiliser price, deforestation, biofuel production and potential yield.

The population grows according to the median scenario projected by the United Nations (United Nations, Department of Economic and Social affairs, Population Division, 2004). In 2050, the world population amounts to 9.1 billions inhabitants.

The evolution of fertiliser price is econometrically related with the evolution of oil and gas prices. This equation is estimated over the 1971-2011 period based on World Bank data (World Bank, 2013). For future projections, we use oil and gas prices from the Imaclim-R model (Sassi et al., 2010) assuming no climate policy. This method leads to a global increase in fertiliser price by $+210 \%$ between 2005 and 2050. By driving the land-fertiliser substitution, this parameter is critical in the determination of the crop yields and cropland area.

The deforestation rate is exogenously set according to the observed trends over the period 2001-2010 (FAO, 2010), assuming that reforestation that occurs in some regions (such as in the US or China) ceases after 2020. The evolution of arable surfaces is directly deduced from reforestation/deforestation rates. Even if cities generally expand on highly fertile lands, we neglect in this study the expansion of urban areas based on the projections done by Thomson et al. (2011) and Masui et al. (2011), in which the urban area remains negligible in comparison to the total agricultural area.

Overall, the area of forest decreases by $8 \%$ between the beginning of the $2000 \mathrm{~s}$ and 2050 (see Supplementary Materials), the decrease is particularly acute in Brazil, Africa and Asia. On the other hand, the area of forest increases slightly in Europe, India and in the USA. According to this senario, the increase in forest area is particularly high in China ( $+34 \%$ over the period studied), reflecting the high reforestation rate recently reported in Chinese data.

Because it is difficult to sketch plausible biofuel scenarios due to the issue of indirect land-use changes (Searchinger et al., 2008), which have brought great uncer- 
tainties in the development of biofuel, and because we mainly focus on food demand, biofuel production is set constant at its 2001 level in the reference scenario.

Potential crop yields, which are used to parameterise the computation of actual yield, are set to be constant over the simulation period, given the uncertainties surrounding the impact of climate change on land productivity and the outlook for futher genetic or agronomic progress (Nelson et al., 2009). The impact of this assumption on the results is tested in the sensitivity analysis.

Finally, feed efficiency parameters evolve linearly to 2030 following Bouwman et al. (2005).

\section{Results}

Simulation results, displayed on Figure 5, depict a large range of possible changes in the agricultural system. Depending on the diet scenario modeled, projected cropland area needs in 2050 range from $\sim 2000$ Mha to $\sim 2900$ Mha, the yield gap from $60 \%$ to $\sim 20 \%$, the intensification of livestock production from $73 \%$ to $98 \%$ and the consumption of fertiliser from $\sim 200 \mathrm{Mt} / \mathrm{yr}$ to $\sim 1500 \mathrm{Mt} / \mathrm{yr}$.

At the upper bound, the "USConv" scenario is associated with major changes both at the intensive and extensive margins to meet an increase in crop production by $140 \%$ between 2005 and 2050. In this scenario, the cropland area expands by 1370 Mha, which corresponds to a near doubling, while the total consumption of fertiliser inputs is multiplied by 10 . Within the agricultural lands, the production potential is almost fully exploited: the yield gap falls from $58 \%$ in 2005 to $21 \%$ in 2050 , and intensive ruminant production grows from $85 \%$ to $98 \%$ of total ruminant production.

At the lower bound, the AG1 diet scenario caused modest changes in the agricultural system. This scenario leads to a growth in crop production by $+48 \%$ over 2005-2050, which weakly spurs the pressure on land. In this context, the expansion of cropland area is mainly driven by the land-fertiliser substitution propelled by high fertiliser prices rather than by the diet scenario ${ }^{4}$. Under the influence of high fertiliser prices and a rather low pressure on land, the consumption of fertiliser inputs increase moderately compared with the other scenarios $(+25 \%$ between 2005 and 2050). As a result, the yield gap experiences a moderate increase from $58 \%$ to $60 \%$ and the production of ruminants becomes increasingly extensive.

[Insert Figure 5 here : Changes in cropland area (5.A), share of intensive ruminant production in total ruminant production (5.B), yield gap (5.C) and consumption of chemical inputs (5.D) in the four diet scenario studied.]

Between these two bounds, the FAO scenario and the MEA_GO can be con-

\footnotetext{
${ }^{4}$ When the fertiliser prices are set constant over the projection period, there is no more cropland expansion
} 
sidered as alternative visions of the business-as-usual scenario, with the MEA_GO scenario being relatively more impacted by globalisation and diet convergence than the FAO scenario. According to our results, the crop production in the MEA_GO scenario increases by $90 \%$ between 2005 and 2050. To meet this production growth, the cropland area expands by 1 billion hectares by 2050 (against $\sim+200 \mathrm{Mha}$ between 1961-2005) and the agriculture keeps intensifying with a yield gap falling from $58 \%$ to $47 \%$ in 2050 and the share of intensive ruminant production rising from $85 \%$ to $95 \%$. To support such an intensification of production, the global consumption of fertiliser is multiplied by 3 over $2005-2050$ (against $\times 5$ between 1961-2005), reaching $\sim 470 \mathrm{Mt} / \mathrm{yr}$ in $2050^{5}$.

Our results on cropland area and fertiliser consumption in the MEA_GO are similar to Tilman et al. in its "Past Trends" scenario ${ }^{6}$. The driving forces of agricultural change at play are nonetheless different: the yield-fertiliser relationship in NLU is more non-linear than in Tilman et al. $(2011)\left(\sim \mathrm{N}^{0.5}\right.$ against $\left.\mathrm{N}^{0.75}\right)$ which tends to accelerate the fertiliser consumption in NLU, but the strong rise in fertiliser price associated with the land-fertiliser substitution, which is modeled in NLU and not in Tilman et al. (2011), slows the consumption of mineral nutrients. On the other hand, our results differ significantly from the MEA, according to which the cropland area is nearly steady between 2005 and $2050^{7}$ and the total fertiliser consumption is around 2 times lower than our results (and thus a $\sim 20 \%$ lower fertiliser consumption per hectare). These discrepancies are mainly attributable to lower assumptions on demographic growth in the MEA (see section 2.1). They are also explained by diverging assumptions on yield changes, with a probable higher growth in potential crop yield in the MEA.

In the FAO diet scenario, the increase in crop production to 2050 is lower than in the MEA_GO scenario ( $+57 \%$ ), thus inducing fewer changes in the agricultural system: the yield gap falls slightly to $57 \%$, the share of intensive ruminant production in total ruminant production rises from $85 \%$ to $89 \%$ and the total fertiliser consumption grows from $\sim 160 \mathrm{Mt} / \mathrm{yr}$ in 2001 to $\sim 260 \mathrm{Mt} / \mathrm{yr}$ in 2050 . The rise in cropland area remains strong with $\sim 600$ million additional hectares between 2005 and 2050, but is mainly due to the rise in fertiliser price and the land-fertiliser substitution, as in the AG1 scenario.

These changes in cropland area are significantly larger than those projected by Alexandratos and Bruinsma (2012) (+70 Mha between 2005 and 2050). This discrepancy is explained by our representation of farmers' trade-off on fertiliser prices, which leads to lower consumption per cultivated hectare $(\sim 130 \mathrm{~kg} / \mathrm{ha} / \mathrm{yr}$ against $190 \mathrm{~kg} / \mathrm{ha} / \mathrm{yr}$ in Alexandratos and Bruinsma (2012)), and, therefore, to a larger cropland area.

\footnotetext{
${ }^{5} \mathrm{By}$ considering that $60 \%$ of the fertiliser inputs is composed of $\mathrm{N}$, this figure correspond to a global $\mathrm{N}$ consumption of $\sim 280 \mathrm{Mt} / \mathrm{yr}$.

${ }^{6}$ In Tilman et al., the growth in crop production is slightly higher than in our MEA_GO scenario

${ }^{7}$ According to MA Board (2005, Figure 9.17, p. 326), however, the text p.325 states that in the Global Orchestration scenario, "rapid income growth and stronger preferences for meat result in growing demand for food and feed, leading to a rapid expansion of crop area in all regions".
} 
The analysis at the regional scale reveals a large diversity of situations. In particular, we see a segmentation in 2050 between the Western and Asian regions on the one hand, which are the closest to their potential crop yield in all diet scenarios, and on the other hand, the African and Latin American ones, with relatively higher yield gaps (see Figure 6). This segmentation is due to several reasons. Even if Western countries and China experience a modest relative increase in food demand in each diet scenario, their yield gaps are initially among the lowest, and the extensification of cropland area is constrained by the reforestation occurring in these countries according to our scenario, and the relatively low reserve of extensive pastures that could potentially be converted into cropland. India and the rest of the Asian countries are, for their part, impacted by high relative increase in food demand in each diet scenario and by relatively low possibilities to extensify the crop production due to the stability of forest area (India) and/ or relatively low reserves of extensive pastures (India and Rest of Asia). These results at the regional scale are robust to our scenario of forest evolution, as we find similar patterns with a forest scenario based on the representative concentration pathways 4.5 (see scenario description in Supplementary Materials).

In terms of animal intensification, the situation is relatively homogenous, except in Pacific OECD and Brazil, where ruminant production is more extensive than in the other regions in all the diet scenarios studied (see Figure 7). In these two regions, the extensive ruminant production system is partly preserved because of the substantial deforestation assumed to 2050 and their relatively moderate increase in food demand.

[Insert Figure 6 here : Yield gap in 2005 and in 2050 according to the four diet scenarios studied.]

\section{[Insert Figure 7 here : Share of intensive ruminant production in total ruminant production in 2005 and in 2050 according to the four diet scenarios studied.]}

The growth of trade in plant food calories ranges between $+80 \%$ (FAO) and $+280 \%$ (USConv), against $+460 \%$ between 1961 and 2005 (for a growth in plant food production by $+150 \%$ ). Overall, the diet scenarios have little influence on the direction of trade flows, apart from some exceptions (e.g., Europe and Pacific OECD become net exporters in the AG1 scenario, while they are net importer in the other diet scenarios).

As expected, the main net exporters in 2050 (in proportion of the domestic production) are the Latin American countries, USA and Canada (see Figure 8), while the main net importers are India and the Middle East. In spite of its large production reserves, Africa is a net importer in all diet scenarios, as this region also faces the largest increase in food demand, compared to the other regions, in all the diet scenarios. 
Our results on international trade are quite similar with those of Alexandratos and Bruinsma (2012) for cereals. A noticeable discrepancy concerns Europe which is a net (minor) exporter in 2050 according to Alexandratos and Bruinsma (2012) while it is a net importer in all our scenarios in 2050 except AG1. The growth of trade in plant food products in the MEA_GO scenario is similar with the growth in grain trade of the MEA "Global Orchestration" scenario (+200\% from 1997 to 2050 against $+160 \%$ from 2005 to 2050 in our simulation). However, sub-Saharan Africa becomes a net exporter in 2050 in the MEA, while it is a net importer in our simulations.

[Insert Figure 8 here : Trade balance of plant food products on plant food production in 2005 and in 2050 according to the four diet scenarios studied (dynamic crops).]

\section{Sensitivity Analysis}

To study the interactions between the diet scenarios and the other use of land, we test alternative scenarios of forest evolution and biofuel production.

The variant on deforestation is based on a scenario corresponding to the Representative Concentration Pathway (RCP) 4.5 (Thomson et al., 2011) (see Supplementary Materials). This scenario forecasts an increase in forest area by $+7 \%$ to 2050 (against a decrease by $8 \%$ in the reference scenario). In this variant, reforestation occurs everywhere except in China where the area of forest decreases slightly (-4\%).

The variant on biofuel (named "High biofuel") is based on a scenario adapted from IEA/OECD (2008). In this variant, only first generation biofuels are considered, with total production reaching 150 Mtoe (2 Ecal) in 2050, i.e. between $14.7 \%$ (AG1) and $7.9 \%$ (USConv) of the total calorie production.

To complete the analysis, we run a sensitivity analysis on two parameters, which are seen to be of determinant importance to mitigate the tensions on land-use. The first one is the evolution of the potential crop yield. To test its influence on the results, we built a scenario assuming that the potential crop yield will grow by $12 \%$ in the developed countries and by $25 \%$ in the developing ones (denoted "High Pot. Yield" in tables 1 and 2). For these latter countries, this corresponds approximately to half of the growth in crop yield due to the introduction of modern varieties reported by Evenson and Gollin (2003) between 1981 and 2000, although this study does not separate increase in yield due to better nutrient take-off and increase in yield at constant fertiliser input.

The second parameter tested is nutrient use efficiency (NUE). A variation in NUE is modeled by modifying the slope at the origin of the yield-fertiliser relationship. Based on the PNUD recommandations (Sutton et al., 2013), we test a scenario assuming an increase by $20 \%$ to 2020 of the NUE.

For the sake of simplicity, we focus on the yield gap and the world calorie price. This latter value can actually be considered a good indicator of the tensions on 
land-use. In NLU, an increase in calorie price is associated, all other things being equal, with the enhancement of agricultural production through larger amounts of chemical inputs, larger cropland area and more intensified livestock production.

As shown in tables 1 and 2, the results suggest that the consequences of reforestation or of the growth in biofuel production are larger when the proportion of animal calories in food diets is high. The variant on forest evolution leads to a $5 \%$ points decrease in yield gap and an $18 \%$ increase in calorie price in the AG1 scenario while it leads to a $13 \%$ points decrease in yield gap and a $140 \%$ increase in calorie price in the MEA_GO scenario. The model was not able to find a solution in the case of the USConv scenario as the demand cannot be met with such a contraction of the agricultural areas. Similar patterns can be observed in the case of growth in biofuel production, with a small impact in the case of the AG1 scenario ( $-2 \%$ points in yield gap $/+12 \%$ points in calorie price) versus a strong impact in the case of the USConv scenario ( $-8 \%$ points in yield gap $/+160 \%$ points in calorie price).

This differential impact of biofuel production and reforestation on agriculture is due to the non-linearities that are represented in NLU, namely the yield fertiliser function and the land availability that make the growth in production more difficult (in terms of fertiliser inputs and additional land needed) as one gets closer to the potential yield and to the least productive lands.

Conversely, and for the same reasons, the impact of an increase in potential yield or in NUE is larger in the most gluttonous diet scenarios. Our variant on potential yield appears to be more efficient at reducing the tensions on land-use than a $+20 \%$ increase in NUE. This variant on potential yield more than compensates for the pressure on land resulting from our variant on biofuel (see last lines of tables 1 and 2).

[Insert Table 1 here : Yield gap]

\section{[Insert Table 2 here : Calorie price in \$/Gcal]}

\section{Conclusion}

Shifts in diet are a key issue in many fields. The higher consumption of fat-rich animal products, the pressure on food markets and on the agricultural production system generated by a higher food demand are sources of concerns for public health, food security, and climate change.

Among the main recent projections of food consumption, the estimated growth in food availability between 2005-2050 varies twofold (from $+9 \%$ to $+20 \%$ ) (MA Board, 2005; Tilman et al., 2011; Alexandratos and Bruinsma, 2012). The range of possible "food future" is even larger by considering more stringent assumptions on diet convergence, from a quasi-stability, with a scenario based on a convergence towards sustainable feeding conditions, to $+45 \%$, with a scenario of convergence 
towards US food habits in 2005. The range of possible futures is the highest for animal calories which are central in the diet convergence process, as their production process is particularly land-intensive.

In this paper, we evaluated the impact on agriculture of these diet scenarios, each based on distinct assumptions on the influence of globalisation on diets. Our results provide extremely contrasting visions of the 2050 agricultural system. According to the diet scenarios, and with same assumptions on the other parameters (population, fertiliser price, etc), the possible cropland area in 2050 ranges from $\sim 2000$ Mha to $\sim 2900$ Mha, the yield gap from $20 \%$ to $\sim 60 \%$, the intensification of livestock production from $73 \%$ to $98 \%$ and the consumption of fertiliser from $\sim 200 \mathrm{Mt} / \mathrm{yr}$ to $\sim 1500 \mathrm{Mt} / \mathrm{yr}$. As expected, the largest impact on ecosystems are associated with the strongest convergence towards western diets.

Testing the sensitivity of our results to assumptions regarding biofuel production, deforestation, potential crop yields and nutrient use efficiency provides numerous insights. First, the impacts of biofuel development and policies reducing deforestation on agriculture increase more than proportionaly when diets become more land-intensive, due to the non-linear effects linked to the limited land availability and the yield-fertiliser relationship. In other words, the different uses of land become increasingly interdependent, as the tensions on agriculture and land grow, because the amount of land and fertiliser required to produce one unit of biomass is larger in a highly constrained system. Then, our analysis shows that a yearly growth in potential yield corresponding roughly to half of what have been achieved during the Green Revolution is more efficient than a $20 \%$ increase in nutrient use efficiency to reduce the tensions on land-use. However, the realism of those strategies remains to be assessed.

Even though benefits of changing diets have been stressed by many studies (Stehfest et al., 2009; Popp et al., 2010), there is no clear consensus on the legitimacy and need for public action on diets - beyond strict health related issues - as it may be considered as impinging on individual liberties in many countries. Even if diet changes were put forward on the political agenda, this would require finding the correct incentives to do so, as the price mechanisms alone may not be sufficient (Smil, 2002; Stehfest et al., 2009).

Overall, this paper sheds light on the pivotal role of diet changes as drivers of tensions on agriculture and land-use, and shows the uncertainty associated with processes of diet convergence for foresight exercises on food and agriculture. Other interesting questions would be to assess the influence of globalisation on agriculture through alternative channels, such as technological change or international trade. Globalisation could actually facilitate the diffusion of agronomic innovation among countries, and in so doing, spur increases in potential crop yield or reductions in nutrient consumption. Verburg et al. (2009) studied the impact of agricultural trade liberalisation on land-use and greenhouse gas emission using the coupled LEITAPIMAGE modelling system. Their results indicate that liberalisation triggers a shift in production from North America and Europe to Latin America leading to an overall expansion of agricultural area and a global increase in total GHG emissions 
by about $6 \%$ compared to the reference scenario value in 2015 . This study is however very careful in formulating general conclusions, as their results crucially depend on the types of liberalisation that is considered. 


\section{References}

Alexandratos, N. and Bruinsma, J. (2012). World agriculture towards 2030/2050. the 2012 revision. Technical report, FAO. ESA Working paper No. 12-03.

Bouwman, A., der Hoek, K. V., Eickhout, B., and Soenario, I. (2005). Exploring changes in world ruminant production systems. Agricultural Systems, 84(2):121153.

Dorin, B. (2011). Agribiom caloric balance sheets. In Paillard et al. (2011b), pages 25-65. Updated estimates from "Agribiom: a tool for scenario-building and hybrid modelling".

Evenson, R. E. and Gollin, D. (2003). Assessing the impact of the green revolution. Science New Series, 300:758-762.

FAO, F. (2010). Global forest resources assessment 2010. Working Papers FAO Forestry paper 163 , FAO.

IEA/OECD (2008). World Energy Outlook. IEA, International Energy Agency: OECD, Paris.

Lambin, E. F. and Meyfroidt, P. (2009). Global land use change, economic globalization, and the looming land scarcity. Proceedings of the National Academy of Sciences of the United States of America, 108(9):3465-3472.

MA Board (2005). Ecosystems and Human Well-being: Scenarios, volume 2. Island press.

Masui, T., Matsumoto, K., Hijioka, Y., Kinoshita, T., Nozawa, T., Ishiwatari, S., Kato, E., Shukla, P., Yamagata, Y., and Kainuma, M. (2011). An emission pathway for stabilization at $6 \mathrm{wm} 2$ radiative forcing. Climatic Change, 109(1):59-76.

Nelson, G. C., Rosegrant, M. W., Koo, J., Robertson, R., Sulser, T., Zhu, T., Ringler, C., Msangi, S., Palazzo, A., Batka, M., Magalhaes, M., and Va (2009). Climate change: Impact on agriculture and costs of adaptation. Technical report.

Paillard, S., Dorin, B., Le Cotty, T., Ronzon, T., and Treyer, S. (2011a). Food security by 2050: Insights from the agrimonde project. European Foresight Platform Brief no. 196, CIRAD, INRA.

Paillard, S., Treyer, S., and Dorin, B. (2011b). Agrimonde, Scenarios and Challenges for Feeding the World in 2050. Quae, Versailles.

Popp, A., Lotze-Campen, H., and Bodirsky, B. (2010). Food consumption, diet shifts and associated non-co2 greenhouse gases from agricultural production. Global Environmental Change, 20(3):451 - 462. ¡ce:title¿Governance, Complexity and Resiliencei/ce:titlej. 
Ramankutty, N., Evan, A. T., Monfreda, C., and Foley, J. A. (2008). Farming the planet: 1. geographic distribution of global agricultural lands in the year 2000 . Global Biogeochemical Cycles, 22.

Ramankutty, N. and Foley, J. A. (1999). Estimating historical changes in global land cover: croplands from 1700 to 1992. Global Biogeochemical Cycles, 13(4):997-1027.

Sassi, O., Crassous, R., Hourcade, J.-C., Gitz, V., Waisman, H., and Guivarch, C. (2010). IMACLIM-R: a modelling framework to simulate sustainable development pathways. International Journal of Global Environmental Issues, 10(1/2):5-24.

Searchinger, T., Heimlich, R., Houghton, R. A., Dong, F., Elobeid, A., Fabiosa, J., Tokgoz, S., Hayes, D., and Yu, T.-H. (2008). Use of U.S. croplands for biofuels increases greenhouse gases through emissions from land-use change. Science, 319(5867):1238-1240.

Smil, V. (2002). Eating meat: Evolution, patterns, and consequences. Population and Development Review, 28(4):599-639.

Souty, F., Brunelle, T., Dumas, P., Dorin, B., Ciais, P., Crassous, R., Müller, C., and Bondeau, A. (2012). The nexus land-use model version 1.0, an approach articulating biophysical potentials and economic dynamics to model competition for land-use. Geoscientific Model Development, 5(5):1297-1322.

Stehfest, E., Bouwman, L., van Vuuren, D., den Elzen, M., Eickhout, B., and Kabat, P. (2009). Climate benefits of changing diet. Climatic Change, 95(1):83-102.

Stephan, H., Weaver, P., Bartelson, J., and Faran, T. (2011). Final report on globalisation and sustainable development informed by sustainability. Technical report, Globis research consortium.

Sutton, M., Bleeker, A., Howard, C., Bekunda, M., Grizzetti, B., de Vries, W., van Grinsven, H., Abrol, Y., Adhya, T., Billen, G., Davidson, E., Datta, A., Diaz, R., Erisman, J., Liu, X., Oenema, O., Palm, C., Raghuram, N., Reis, S., Scholz, R., Sims, T., Westhoek, H., Zhang, F., Ayyappan, S., Bouwman, A., Bustamante, M., Fowler, D., Galloway, J., Gavito, M., Garnier, J., Greenwood, S., Hellums, D., Holland, M., Hoysall, C., Jaramillo, V., Klimont, Z., Ometto, J., Pathak, H., Fichelet, V. P., Powlson, D., Ramakrishna, K., Roy, A., Sanders, K., Sharma, C., Singh, B., Singh, U., Yan, X., and Zhang, Y. (2013). Our nutrient world: the challenge to produce more food and energy with less pollution. Technical report, Global Partnership on Nutrient Management and the International Nitrogen Initiative, Edinburgh. Global Overview of Nutrient Management.

Thomson, A., Calvin, K., Smith, S., Kyle, G., Volke, A., Patel, P., Delgado-Arias, S., Bond-Lamberty, B., Wise, M., Clarke, L., and Edmonds, J. (2011). Rcp4.5: a pathway for stabilization of radiative forcing by 2100. Climatic Change, 109(1):7794 . 
Tilman, D., Balzer, C., Hill, J., and Befort, B. L. (2011). Global food demand and the sustainable intensification of agriculture. Proceedings of the National Academy of Sciences, 108(50):20260-20264.

United Nations, Department of Economic and Social affairs, Population Division (2004). World population to 2030. Technical report, United Nations, New York.

Verburg, R., Stehfest, E., Woltjer, G., and Eickhout, B. (2009). The effect of agricultural trade liberalisation on land-use related greenhouse gas emissions. Global Environmental Change, 19(4):434 - 446.

World Bank (2013). Commodity price data 1960-2013. last access: 5 April 2013. 


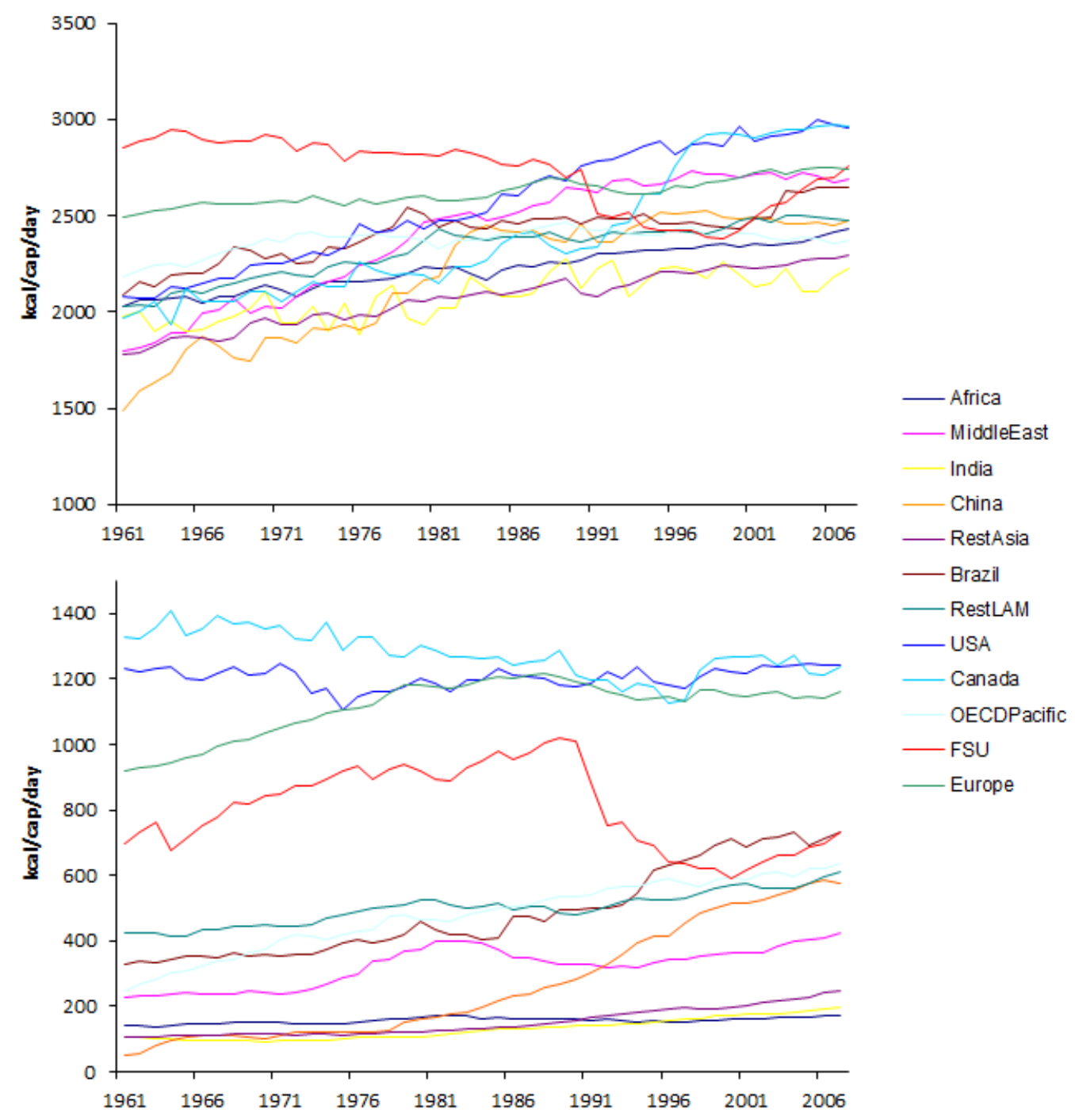

Figure 1: Changes in consumption of plant food (up) and animal (down) calories around the world (Dorin, 2011). 


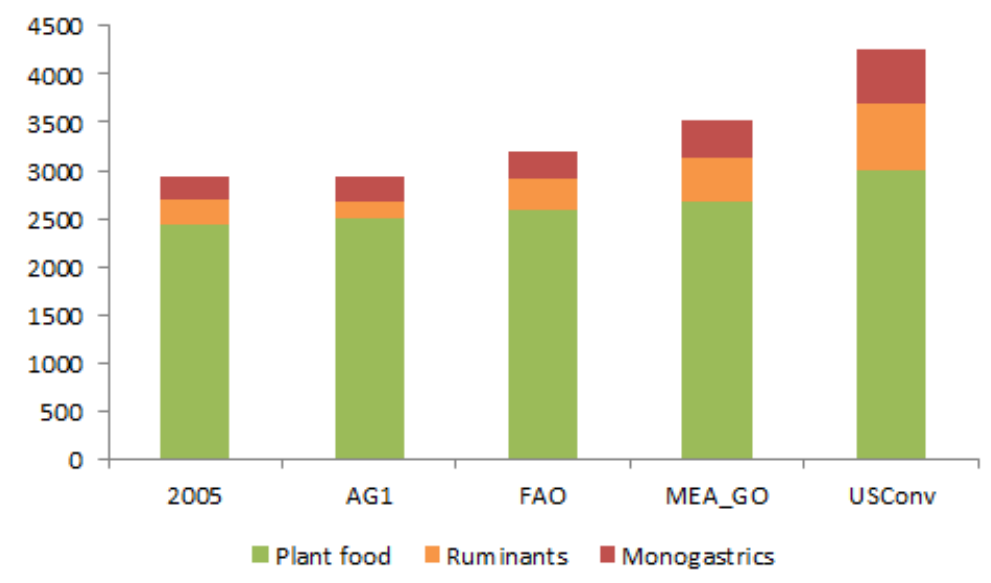

Figure 2: World average food availability in 2005 and in 2050 according to the four diet scenarios studied (in $\mathrm{kcal} / \mathrm{cap} /$ day).
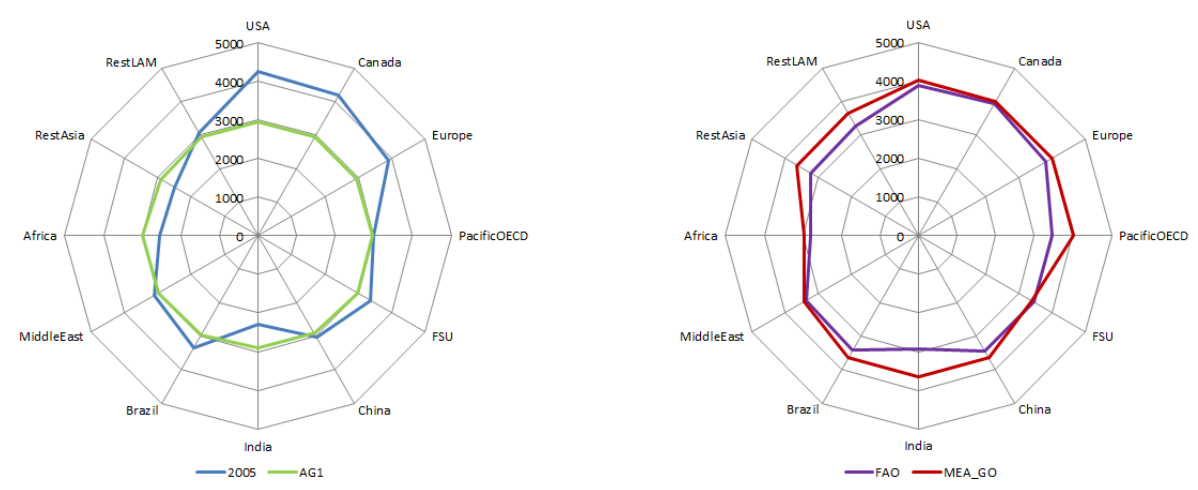

Figure 3: Regional food availabilities of total calories (in kcal/cap/day).
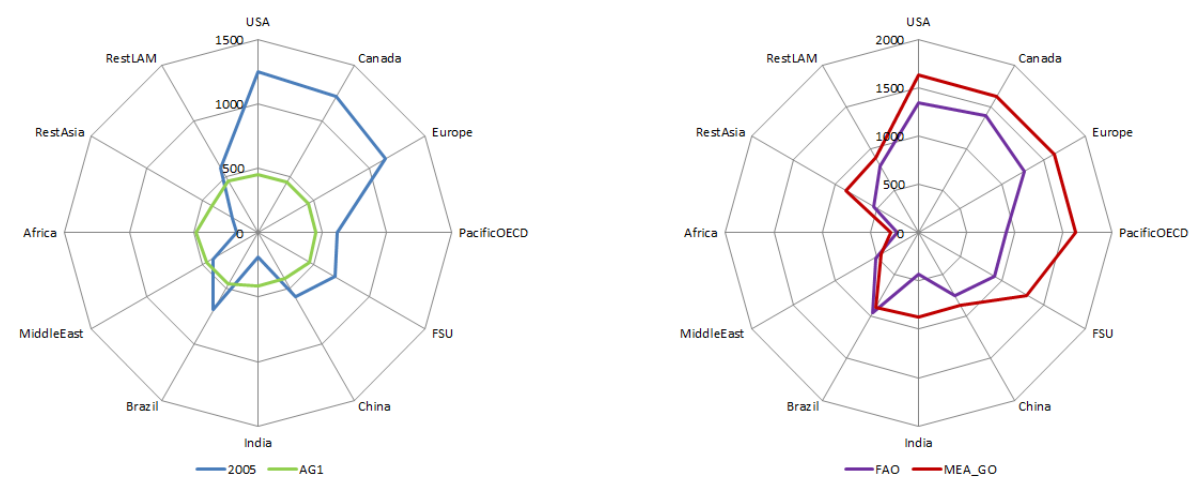

Figure 4: Regional food availabilities of animal calories (in kcal/cap/day). 
$5 . \mathrm{A}$

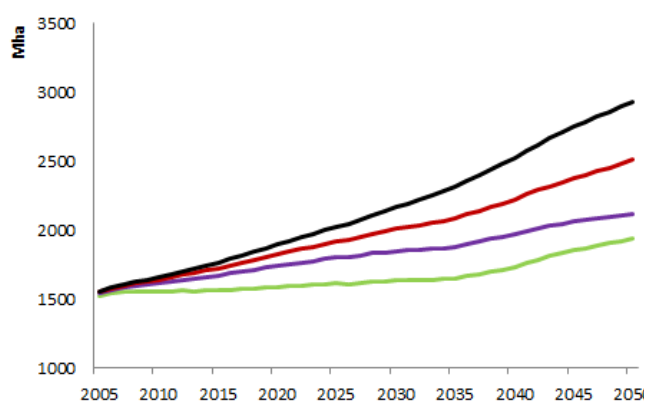

5.C

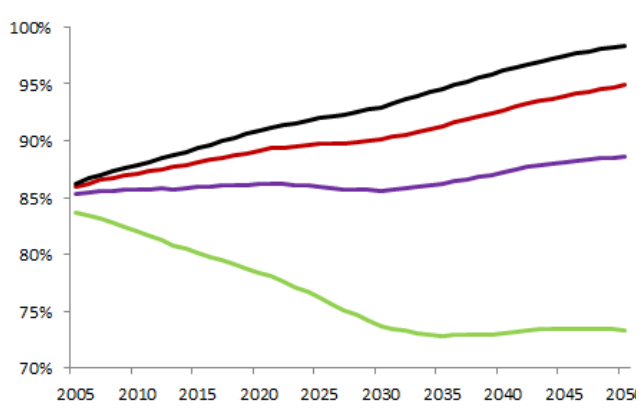

$5 . \mathrm{B}$

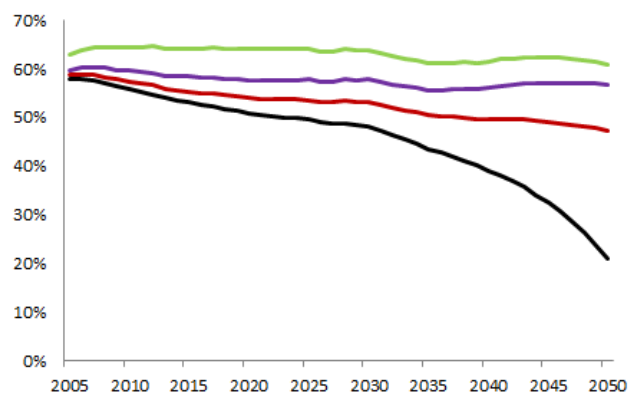

$5 . \mathrm{D}$

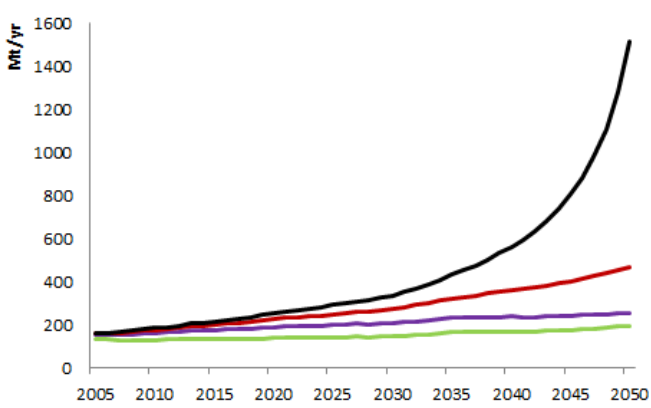

USConv

Figure 5: Changes in cropland area (5.A), share of intensive ruminant production in total ruminant production (5.B), yield gap (5.C) and consumption of chemical inputs (5.D) in the four diet scenario studied.

Table 1: Yield gap

\begin{tabular}{lcccc}
\hline & AG1 & FAO & MEA_GO & USConv \\
\hline Reference & $61 \%$ & $57 \%$ & $47 \%$ & $21 \%$ \\
Reforestation (RCP4.5) & $56 \%$ & $50 \%$ & $34 \%$ & na \\
High biofuel & $59 \%$ & $54 \%$ & $44 \%$ & $13 \%$ \\
High Pot. Yield & $64 \%$ & $60 \%$ & $52 \%$ & $33 \%$ \\
NUE + 20\% & $58 \%$ & $54 \%$ & $45 \%$ & $19 \%$ \\
High Pot. Yield + NUE & $61 \%$ & $57 \%$ & $50 \%$ & $31 \%$ \\
High Pot. Yield + high biofuel & $63 \%$ & $58 \%$ & $50 \%$ & $28 \%$ \\
\hline
\end{tabular}




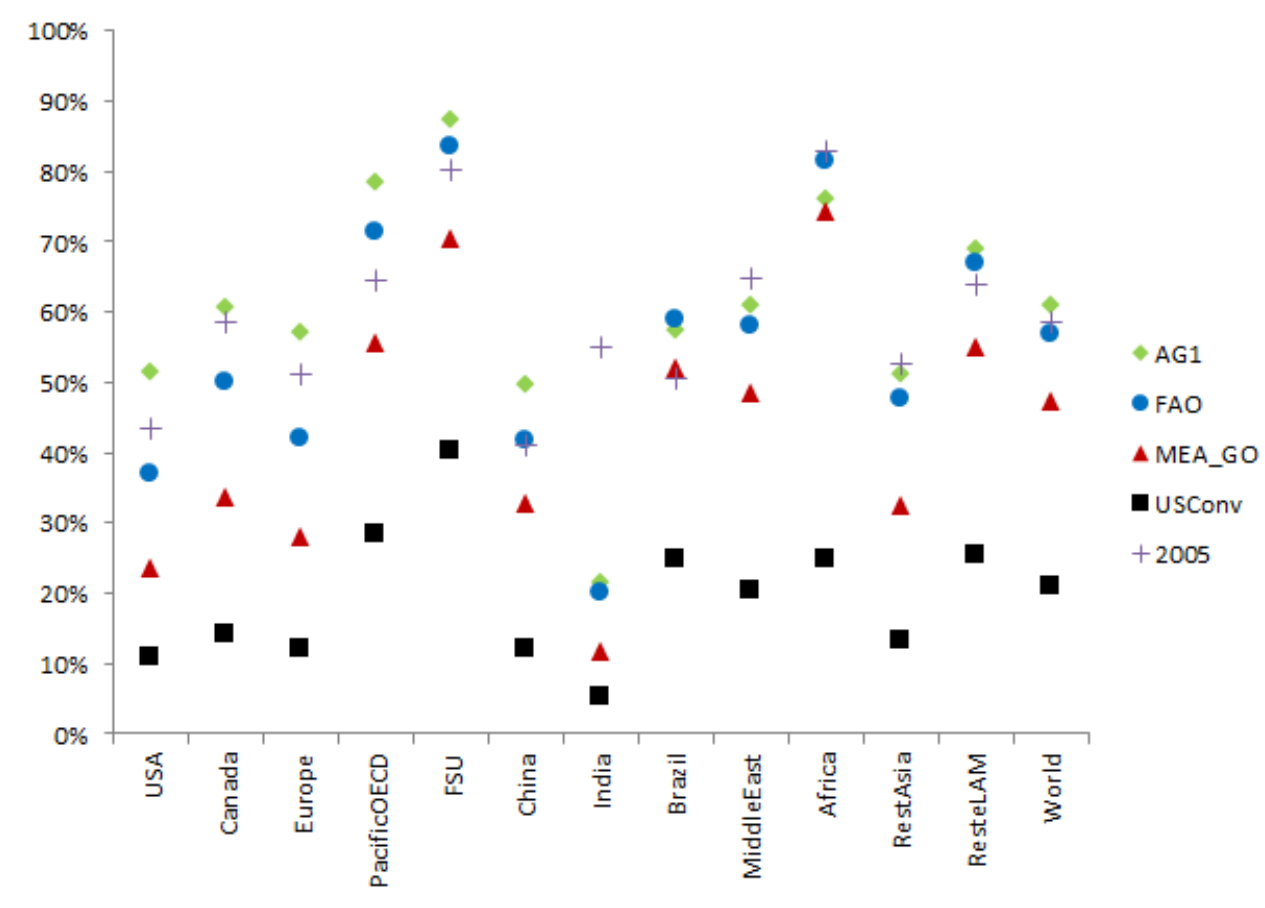

Figure 6: Yield gap in 2005 and in 2050 according to the four diet scenarios studied.

Table 2: Calorie price in $\$ /$ Gcal

\begin{tabular}{lcccc}
\hline & AG1 & FAO & MEA_GO & USConv \\
\hline Reference & 40 & 56 & 100 & 476 \\
Reforestation (RCP4.5) & 47 & 80 & 242 & na \\
High biofuel & 45 & 65 & 126 & 1235 \\
High Pot. Yield & 37 & 47 & 76 & 184 \\
NUE +20\% & 37 & 52 & 92 & 462 \\
High Pot. Yield + NUE & 32 & 44 & 70 & 171 \\
High Pot. Yield + high biofuel & 38 & 54 & 89 & 270 \\
\hline
\end{tabular}




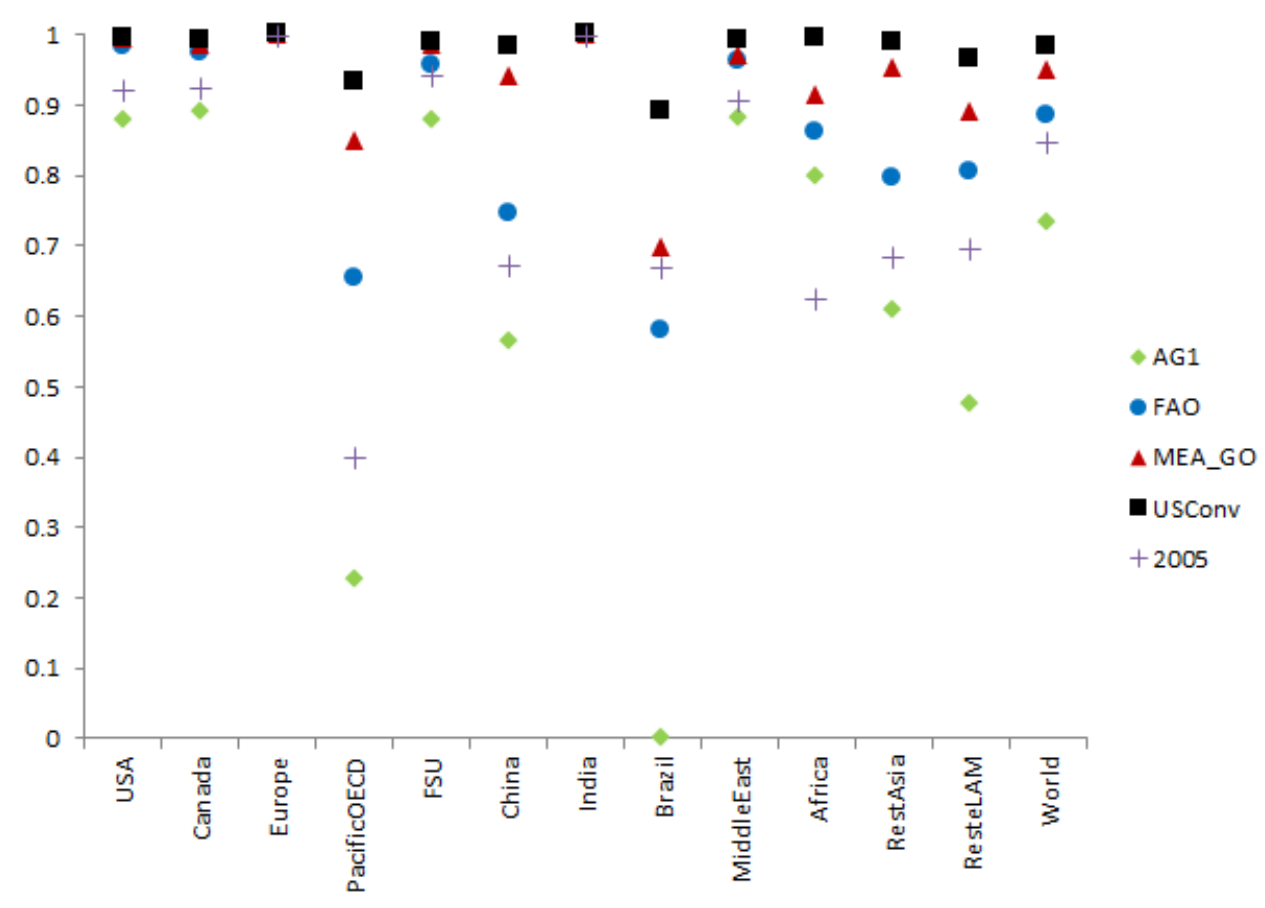

Figure 7: Share of intensive ruminant production in total ruminant production in 2005 and in 2050 according to the four diet scenarios studied. 


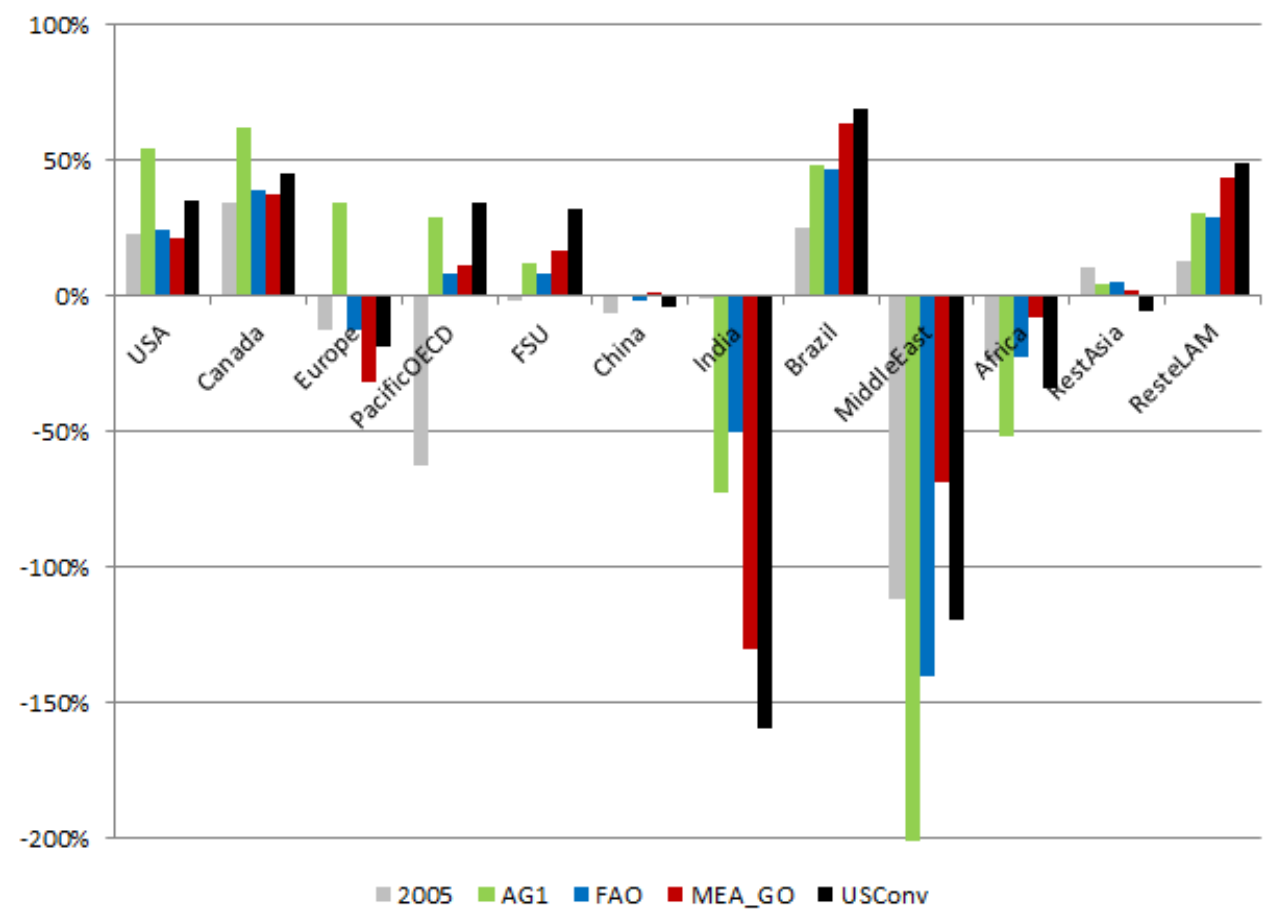

Figure 8: Trade balance of plant food products on plant food production in 2005 and in 2050 according to the four diet scenarios studied (dynamic crops). 